\section{Recognition ratings and imagery mediation with pictures and words}

\author{
FRANK W. WICKER* and FREDA M. HOLLEY \\ University of Texas at Austin, Austin, Tex. 78712
}

The effect of stimulus recognition ratings on immediately subsequent response recall in the test-trial of paired-associate learning was evaluated with picture and word stimuli in conjunction with two visual distracting tasks. Recall was reduced by the recognition ratings, but this effect appeared independent of stimulus modality and of visual distraction. It was suggested that the recognition task may disrupt use of imagery mediation but that this disruption does not differ for pictures and words.

An experiment by Wicker (1970) attempted to define a theoretical locus of the superiority of picture stimuli over corresponding word stimuli in paired-associate learning (PAL) by varying mode of stimulus presentation (pictorial vs verbal) in study periods and in test periods and by giving a recognition test immediately before each attempt at recall. That study began with the hypothesis from perceptual learning theorists (e.g., Asch, 1968) that correct recall depends upon prior recognition of the stimulus term. Even though Bahrick (1969) has shown that associative learning proceeds independently of discriminative learning after an initial gross differentiation among stimulus items, it was assumed that associative activation during a test trial of PAL was dependent upon this initial differentiation or recognition process. The data revealed that an overall picture advantage in cueing recall disappeared when considering only pairs rated as definitely recognized, and it was inferred that picture superiority was localized in the recognition process independent of an associative phase during recall. This interpretation contradicts any explanation of the picture-word difference which implicates such an associative phase, including the attempt to account for the difference in terms of mediational imagery. Although Paivio (1971, p. 293) pointed out that the use of numbers and letters as response terms in the Wicker (1970) study may have reduced the role of mediational imagery, comparable results have also been obtained with concrete nouns as response terms (Wicker, 1971a; Wicker \& Evertson, 1972).

Other interpretations of these results have considered the possibility of methodological artifacts. Stimulus

* Requests for reprints should be sent to Frank W. Wicker, Department of Educational Psychology, University of Texas, Austin, Tex. 78712 . recognition ratings may be affected by response recall, but Martin (1967) and Royer (1969) did not find a relationship between recognizability of stimulus items and the stability of associations to them, and Wicker $(1970,1971 a)$ showed that the superiority of stimulus recognition with pictures was at least as great when considering only pairs for which correct recall was not obtained. Reinterpretation would also be necessary if recognition ratings were affected by imagery mediation. Winograd, Karchmer, \& Russell (1971) showed that imagery instructions improved recognition when images related the to-be-recognized word with a simultaneously presented cue word. Without such cueing, however, both Bowver (1979) and W/icker (1971a) found that imagery instructions affected only associative learning and did not increase stimulus recognition. It is also possible that picture-word recognition differences lead to differential item selection in terms of associative difficulty, but Wicker (1971b) presented data which indicated that associative differences were independent of the recognition difficulty of items.

An ingenious suggestion by Yarmey (1971), however, could reconcile an imagery interpretation of picture-word differences with the Wicker (1970, 1971a) results. Yarmey replicated the finding that control for recognition eliminated the picture advantage, but implied that disruption of imagery mediation or a change in preferred mode of memory coding due to the recognition rating task may account for this outcome.

The present study attempted to examine this possibility by comparing groups giving contiguous recognition and recall responses with a group in which only recall was tested (the test-trial procedure factor). If greater imagery mediation is typically responsible for greater recall with picture stimuli and if this imagery advantage is destroyed by a iecognition task, then test-trial procedure can be expected to interact with stimulus modality; that is, a greater picture-word difference would be obtained in the recall-only condition.

In the present experiment, two distracting tasks were introduced during the study trial. If visual distracting tasks have a disruptive effect on imagery production (Wicker \& Holley, 1971), then distraction might interact with the other factors of this study.

\section{METHOD}

Sixty undergraduate students of educational psychology participated in the experiment. After standard PAL instructions, each $\mathrm{S}$ had two study-test trials with one of two mixed lists of 15 word-word pairs and 15 picture-word pairs. Each picture stimulus in one list matched a corresponding word stimulus in the other. The stimuli, on $35 \cdot \mathrm{mm}$ slides, were identical to those used by Wicker \& Holley (1971). They were projected in a randomly determined order onto a daylight screen from a Carousel slide projector advanced by a Lafayette repeat-cycle timer.

Three distractor conditions were employed as a within-list variable. Pairs presented for $2 \mathrm{sec}$ followed by $4 \mathrm{sec}$ for undistracted study were called $\mathrm{N}$ pairs. Those shown for $2 \mathrm{sec}$ followed by a 2 -sec presentation of a simple abstract design and 2 sec more for copying the design and rehearsing the pair were called $\mathrm{V}$ pairs. Those for which the 2 -sec presentation was followed by a 2 -sec visual presentation of a six-digit number and $2 \mathrm{sec}$ more for copying the number were called pairs. Thus, each list of 30 pairs contained five word-word pairs and five picture-word pairs of each of three distraction types. For each type of pair, Ss had 6 sec to study the pair and to copy any additional stimulus presented on the screen. Four practice items were given prior to the first study trial.

In a recall-only group, 6 sec were given for recall of each response term. In two recognition-recall groups, 15 picture distractors and 15 word distractors were randomly interspersed with the stimulus items during the test period. Ss rated their recognition of each item by circling one of five symbols representing a 5-point scale from DO (definitely old) to DN (definitely new) and then wrote down the associated response term whenever possible. They were asked to give their immediate first impressions as to recognition in order to maximize the time they had available for recall. One group had $6 \mathrm{sec}$ and the other had $7 \mathrm{sec}$ for recognition and recall. The 7 -sec group was chosen to be roughly 
Table 1

Means and Standard Deviations for Recall in Two Trials

\begin{tabular}{|c|c|c|c|c|c|c|}
\hline & \multicolumn{2}{|c|}{$\begin{array}{l}\text { Recall Only } \\
\text { Group }\end{array}$} & \multicolumn{2}{|c|}{$\begin{array}{c}\text { Recognition-Recall } \\
\text { (6-Sec) Group }\end{array}$} & \multicolumn{2}{|c|}{$\begin{array}{c}\text { Recognition-Recall } \\
\text { (7-Sec) Group }\end{array}$} \\
\hline & Picture & Word & Picture & Word & Picture & Word \\
\hline \multicolumn{7}{|l|}{ N Pair } \\
\hline Mean & 5.4 & 4.4 & 3.4 & 2.1 & 2.9 & 2.3 \\
\hline SD & 2.5 & 2.8 & 2.4 & 2.1 & 2.2 & 2.5 \\
\hline \multicolumn{7}{|l|}{ \# Pair } \\
\hline Mean & 4.5 & 3.7 & 2.8 & 2.3 & 2.1 & 2.0 \\
\hline SD & 2.5 & 2.8 & 2.5 & 2.5 & 1.8 & 1.9 \\
\hline \multicolumn{7}{|l|}{ V Pair } \\
\hline Mean & 4.1 & 3.9 & 2.5 & 2.2 & 2.0 & 1.7 \\
\hline SD & 2.8 & 2.7 & 2.2 & 2.5 & 1.4 & 2.0 \\
\hline
\end{tabular}

equal to the recall-only group in time available for recall, because informal pilot data had indicated that only about $1 \mathrm{sec}$ was used for the recognition response with the instructions of this study. All three groups recorded their responses on IBM cards which were turned face down so that previous responses were not visible. Finally, Ss rated their previous use of imagery on a postexperimental questionnaire by circling a digit from 0 ("definitely no image") to 4 ("a very clear, strong image") following each pair on an answer sheet. Ss were assigned to one of six conditions, based on the three test-trial procedures and the two lists.

RESULTS AND DISCUSSION

Table 1 presents means and standard deviations of recall scores for several conditions, averaging over lists. Significant main effects were found for stimulus modality $[F(1,57)=9.44$, $\mathrm{p}<.01]$, distraction $[\mathrm{F}(2,114)=$ $8.99, \mathrm{p}<.001]$, and for test-trial procedure $[F(2,57)=6.25, p<.01]$. Word stimuli, distracting tasks, and the recognition test were all associated with poorer recall. With the indices of recognition given in Table 2 , there were reliable main effects for stimulus modality $[F(1,38)=59.88, p<.001]$ and for distraction $[\mathrm{F}(2,76)=4.63$, $\mathrm{p}<.05]$. The effect of distracting tasks on recognition may indicate that these tasks disrupt other processes in addition to imagery mediation.

Table 2

Means and Standard Deviations for Number of DO Recognition Ratings in Two Trials

\begin{tabular}{|c|c|c|c|c|}
\hline & \multicolumn{2}{|c|}{ 6-Sec Group } & \multicolumn{2}{|c|}{ 7-Sec Group } \\
\hline & Picture & Word & Picture & Word \\
\hline $\begin{array}{l}N \text { Pair } \\
\text { Mean }\end{array}$ & 8.5 & 6.6 & 8.4 & 5.8 \\
\hline SD & 1.4 & 1.9 & 1.5 & 2.5 \\
\hline $\begin{array}{l}\text { \# Pair } \\
\text { Mean }\end{array}$ & 8.0 & 6.2 & 7.6 & 5.5 \\
\hline SD & 1.5 & 2.5 & 1.7 & 1.9 \\
\hline $\begin{array}{l}V \text { Pair } \\
\text { Mean }\end{array}$ & 7.6 & 5.8 & 7.8 & 5.2 \\
\hline SD & 1.6 & 2.5 & 1.6 & 2.4 \\
\hline
\end{tabular}

Although the Distraction by Stimulus Mode interaction for recall failed of significance $[F(2,114)=2.76$, $.05<\mathrm{p}<.10$ ], a Dunnett's $\mathrm{t}$ test on difference scores did indicate a larger picture-word difference with $\mathrm{N}$ pairs than with $\mathrm{V}$ pairs $(\mathrm{t}=2.43, \mathrm{df}=57$, $\mathrm{p}<.05)$. The $\mathrm{N}$-pair difference did not significantly surpass the difference with \# pairs $(\mathrm{t}=1.64$, n.s. $)$. None of the other interactions approached significance for recognition or for recall.

Means and standard deviations for number of reported images are given for each condition in Table 3 . A rating of 2 or greater on the postexperimental questionnaire was defined as a reported image; thus, these means are for scores having a maximum possible value of 5 in each cell. More images were reported with pictures than with words $[F(1,57)=$ $4.21, \mathrm{p}<.05]$. Although there was a significant effect for distraction $[\mathrm{F}(2,114)=4.85, \quad \mathrm{p}<.01]$, considerable imagery mediation was still reported after visual distraction.

The postexperimental ratings might be taken as a direct indication of greater imagery mediation with pictures than with words, but there is evidence that postexperimental reports of imagery are biased by such factors as degree of prior recall (Wicker \& Evertson, 1972). The reduction in picture-word recall differences which resulted from copying geometrical designs also suggests that more frequent imagery mediation leads to greater susceptibility to visual distraction with pictures. As discussed by Wicker \& Holley (1971), however, this interaction could also reflect more restrictive or less distraction-resistent images to pictures than to words, or a greater increase in interitem interference for pictures with the introduction of the visual designs. The latter interpretation might have been rejected if the number-copying task, which was assumed to require visual processing of items less similar to the drawings, had also produced a significantly greater decrement with pictures than with words, but it did not.

The recall decrement produced by the recognition task may reflect increased interitem interference, a greater retention interval, or other factors, but it is at least consistent with the contention that a recognition test interferes with the use of imagery mediation in retrieval. There were no significant differences in postexperimental imagery ratings due to test-trial procedure $(F<1)$, but Ss had been instructed to base such ratings on study-trial events rather than on test-trial events.

Even if imagery mediation was reduced by the recognition task, however, our data do not indicate a larger reduction for pictures than for words, because there was no suggestion of a Test-Trial Procedure by Stimulus Mode interaction in recall $(\mathrm{F}<1)$ or in postexperimental imagery report $(F<1)$. While it seems possible that there was reduced time for recall and use of imagery mediators in the recognition groups, or that imagery mediation was reduced by recognition responses, it appears that such reductions did not decrease the picture-word difference in recall. Thus, the recognition task apparently did not differentially interfere with imagery mediation to picture and word stimuli, and such differential interference probably does not

Table 3

Means and Standard Deviations for Number of Reported Images

\begin{tabular}{|c|c|c|c|c|c|c|}
\hline & \multicolumn{2}{|c|}{$\begin{array}{l}\text { Recall Only } \\
\text { Group }\end{array}$} & \multicolumn{2}{|c|}{$\begin{array}{l}\text { Recognition-Recall } \\
\text { (6-Sec) Group }\end{array}$} & \multicolumn{2}{|c|}{$\begin{array}{l}\text { Recognition-Recall } \\
\text { (7-Sec) Group }\end{array}$} \\
\hline & Picture & Word & Picture & Word & Picture & Word \\
\hline \multicolumn{7}{|l|}{ N Pair } \\
\hline Mean & 2.5 & 2.4 & 2.8 & 2.3 & 2.6 & 2.2 \\
\hline SD & 1.3 & 1.4 & 1.1 & 1.8 & 1.5 & 1.8 \\
\hline \multicolumn{7}{|l|}{ \# Pair } \\
\hline Mean & 2.6 & 2.1 & 2.6 & 2.0 & 2.1 & 2.1 \\
\hline SD & 1.2 & 1.4 & 1.2 & 1.3 & 1.3 & 1.7 \\
\hline \multicolumn{7}{|l|}{ V Pair } \\
\hline Mean & 2.3 & 1.8 & 2.2 & 2.0 & 1.9 & 1.9 \\
\hline SD & 1.5 & 1.3 & 1.2 & 1.6 & 1.5 & 1.4 \\
\hline
\end{tabular}


account for previous failures to obtain a picture advantage with recall given recognition.

\section{REFERENCES}

ASCH, S. E. The doctrinal tyranny of associationism: Or what is wrong with rote learning. In $T$. $R$. Dixon and $D$. $L$ Horton (Eds.), Verbal behavior and general behavior theory. Englewood Cliffs, N.J: Prentice-Hall, 1968.

BAHRICK, H. P. Discriminative and associative aspects of pictorial paired-associate learning. Journal of Experimental Psychology, 1969, 80, 113-119.

BOWER, G. H. Imagery as a relational organizer in associative learning. Journal of Verbal Learning \& Verbal Behavior, $1970,9,529-533$
MARTIN, E. Reiation between stimulus recognition and paired-associate learning. Journal of Experimental Psychology, 1967, 74, 500-505.

PAIVIO, A. Imagery and verbal processes. New York: Holt, Rinehart \& Winston, 1971.

ROYER, J. M, Associative recall as a function of stimulus recognition. American Journal of Psychology, 1969, 82, 96-103.

WICKER, F. W. On the locus of picture-word differences in paired-associate learning. Journal of Verbal Learning \& Verbal Behavior, $1970,9,52-57$.

WICKER, F. W. Pictures, words, and imagery mediation in paired-associate learning. Perceptual \& Motor Skills, 1971a, 33, 135-144.

WICKER, F. W. Item selection and picture-word differences in recognition and recall. Perceptual \& Motor Skills, $1971 \mathrm{~b}, 33,1207-1208$

WICKER, F. W., \& EVERTSON, C. M. Prerecall and postrecall imagery ratings with pictorial and verbal stimuli in paired-associate learning. Journal of Experimental Psychology, 1972, 92, 75-82.

WICKER, F. W., \& HOLLEY, F. M. Distraction modality and stimulus modality in paired-associate learning. Psychonomic Science, 1971, 25, 218-220. WINOGRAD, E., KARCHMER, M. A., \& RUSSELL, I. S. Role of encoding unitization in cued recognition memory. Journal of Verbal Learning \& Verbal Behavior, 1971, 10, 199-206.

YARMEY, A. D. Effect of pictures and word labels as retrieval cues in paired-associate learning. Paper presented at the meeting of the Canadian Psychological Association, June 1971. 